\title{
Sedimentation processes of hadal environments: a comparison between Kermadec and Atacama Trenches
}

\author{
KAZUMASA OGURI ${ }^{1,2}$, ROBERT TURNEWITSCH ${ }^{3}$, \\ ASHLEY ROWDEN ${ }^{4,5}$, MATTHIAS ZABEL ${ }^{6}$, PERE \\ MASQUE $^{7}$, HEATHER A STEWART ${ }^{8}$, FRANK \\ WENZHÖFER $^{1,9,10}$ AND RONNIE N GLUD ${ }^{1,11}$ \\ ${ }^{1}$ University of Southern Denmark \\ ${ }^{2}$ Japan Agency for Marine-Earth Science and Technology \\ ${ }^{3}$ Scottish Association for Marine Science \\ ${ }^{4}$ National Institute of Water and Atmospheric Research \\ ${ }^{5}$ Victoria University of Wellington \\ ${ }^{6}$ University of Bremen \\ ${ }^{7}$ International Atomic Energy Agency \\ ${ }^{8}$ British Geological Survey \\ ${ }^{9}$ Alfred Wegener Institute Helmholtz Centre for Polar and \\ Marine Research \\ ${ }^{10}$ Max Planck Institute for Marine Microbiology \\ ${ }^{11}$ Tokyo University of Marine Science and Technology \\ Presenting Author: ogurik@biology.sdu.dk
}

Hadal trenches are important deep sea depocenters focusing large amounts of organic materials. However, there only exist relatively few data on the amount and nature of the deposited material. To explore sediment accumulation process and sources of the organic material in two contrasting trench systems we therefore quantified sediment profiles of excess ${ }^{210} \mathrm{~Pb}\left({ }^{210} \mathrm{~Pb}_{\mathrm{ex}}\right)$, the amount and the characteristics of organic materials (TOC, $\mathrm{TN}, \mathrm{C} / \mathrm{N}$ mol ratio and $\delta^{13} \mathrm{C}_{\mathrm{TOC}}$ ) in the mesotrophic off-shore Kermadec Trench and near-shore eutrophic Atacama Trench.

The data resolved a high degree of variations between and within the trench respective systems reflecting highly localized sedimentary environments. Layers indicating constant ${ }^{210} \mathrm{~Pb}_{\mathrm{ex}}$ activities were found in some cores from both trenches indicating rapid burial by past mass wasting events. Layers that were separated by mono exponential declines in ${ }^{210} \mathrm{~Pb}_{\mathrm{ex}}$ values reflect periods of a stable deposition environment. Surprisingly, the $\mathrm{C} / \mathrm{N}$ values and the $\delta^{13} \mathrm{C}_{\mathrm{TOC}}$ profiles in cores from the Kermadec Trench suggested remarkable high contribution of terrestrial organic materials. In contrast, the proxy values in the Atacama Trench suggested relatively high levels organic materials with a marine origin. This difference showed that origin of organic materials and the transport pathways supplied to these trench systems are different.

The sediment focusing ratio estimated from the ${ }^{210} \mathrm{~Pb}_{\mathrm{ex}}$ inventories in the sediment cores and ${ }^{226} \mathrm{Ra}$ disequilibria in the water column ranged between 2.9 and $3.6(n=2)$ in the Kermadec Trench while the range in the Atacama Trench was 1.3 to 2.6 $(n=10)$, respectively. These ratios indicated that lateral transport processes play important roles for sediment accumulation in the both trenches and contribute to very localized deposition environments. 